Revista da Rede Brasileira de História da Geografia e Geografia Histórica

$11 \mid 2019$

Mapas e mapeamentos: conhecer, apresentar e agir

\title{
A cafeicultura e a Estrada União e Indústria:
}

Transformações espaciais e desenvolvimento desigual em meados do século XIX

Coffee production and the União e Indústria Road: Spatial transformations and uneven development in the mid-19 ${ }^{\text {th }}$ century

La caficultura y la Carretera União e Indústria: Transformaciones espaciales y

desarrollo desigual en mediados del siglo XIX

La caféiculture et la Route União e Indústria : Transformations spatiales et inégal développement à la mi-XIX ${ }^{e}$ siècle

\section{Matheus Cavalcanti Bartholomeu}

\section{(2) OpenEdition}

\section{Journals}

Edição electrónica

URL: https://journals.openedition.org/terrabrasilis/3852

DOI: $10.4000 /$ terrabrasilis.3852

ISSN: 2316-7793

Editora

Rede Brasileira de História da Geografia e Geografia Histórica

Refêrencia eletrónica

Matheus Cavalcanti Bartholomeu, «A cafeicultura e a Estrada União e Indústria:», Terra Brasilis [Online], 11 | 2019, posto online no dia 31 agosto 2019, consultado o 05 dezembro 2022. URL: http:// journals.openedition.org/terrabrasilis/3852 ; DOI: https://doi.org/10.4000/terrabrasilis.3852

Este documento foi criado de forma automática no dia 5 dezembro 2022.

All rights reserved 


\section{A cafeicultura e a Estrada União e Indústria:}

Transformações espaciais e desenvolvimento desigual em meados do século XIX

Coffee production and the União e Indústria Road: Spatial transformations and uneven development in the mid-19 ${ }^{\text {th }}$ century

La caficultura y la Carretera União e Indústria: Transformaciones espaciales y desarrollo desigual en mediados del siglo XIX

La caféiculture et la Route União e Indústria : Transformations spatiales et inégal développement à la mi-XIX siècle

Matheus Cavalcanti Bartholomeu

1 Este trabalho se inscreve em um projeto de pesquisa mais amplo, desenvolvido desde 2011 pelo autor, sobre o eixo de urbanização Rio de Janeiro (RJ) - Juiz de Fora (MG). ${ }^{1} \mathrm{Em}$ outros trabalhos, fizemos uma periodização das transformações espaciais deste eixo, no tocante a seu processo de urbanização: ${ }^{2}$ entre 1861 e 1928, período marcado por uma urbanização incipiente; entre 1928 e 1980, definido por uma urbanização consolidada; e de 1980 aos dias atuais, período caracterizado pela metropolização do espaço. A discussão deste trabalho está inserida no primeiro período mencionado. Seu marco inicial é a inauguração, no ano de 1861, da Estrada União e Indústria, entre as cidades de Petrópolis (RJ) e Juiz de Fora (MG), que também inaugura, a nosso ver, o próprio eixo Rio de Janeiro - Juiz de Fora, já que permitiu reduzir significativamente o tempo de viagem e estreitar os laços entre as cidades.

Dois elementos marcam as principais transformações espaciais transcorridas no eixo Rio de Janeiro - Juiz de Fora neste período: o café e a indústria. Eles não se dão sequentemente ou paralelamente, mas no bojo de um mesmo processo: a urbanização, então incipiente, deste espaço. Aqui entendemos urbano e urbanização no sentido mais amplo dado por Lefebvre $(1978,2008,2011)$, que não implica apenas os aspectos materiais e formais. Desse modo, tratar de urbanização incipiente significa tratar de uma problemática urbana que começava a invadir a vida cotidiana e transformar uma 
sociedade ainda predominantemente influenciada pelas dinâmicas, espaços e tempos do rural e da fábrica.

3 O objetivo deste texto é compreender a relação entre a produção cafeeira no vale do Rio Paraíba do Sul fluminense e na Zona da Mata mineira e a construção e operação da Estrada União e Indústria, pioneira no processo de desenvolvimento de uma malha rodoferroviária que se constituiria como condição geral de reprodução do capital associado à cafeicultura. As transformações que se procederam estão inscritas num processo mais amplo de desenvolvimento desigual, com notáveis rebatimentos espaciais. Na primeira parte do artigo, faremos um breve percurso histórico da cafeicultura no Brasil até seu assentamento nas regiões em questão, evidenciando algumas importantes contradições com o desenvolvimento do modo de produção capitalista. Seguidamente, discutiremos a construção da estrada, chamando atenção para a constituição da força de trabalho dessa empreitada e para os condicionantes geomorfológicos que se apresentaram como obstáculos à técnica rodoviária. Por fim, traremos dados e reflexões sobre o período em que a Estrada União e Indústria operou como principal rota de escoamento do café de uma vasta região do interior brasileiro não limitada apenas às proximidades de Juiz de Fora.

\section{0 (contraditório) percurso da cafeicultura no Brasil até meados do século XIX}

4 Inicialmente introduzido como cultivo experimental no próprio município do Rio de Janeiro, em 1760, o café rapidamente despertou o interesse de alguns fazendeiros. Com vistas ao mercado externo, eles ampliaram até 1840 sua produção para os Maciços da Tijuca, da Pedra Branca e do Mendanha, para a frente dissecada da Serra do Mar e para o maciço de Itaboraí, Maricá e São Gonçalo (RJ), deixando grandes áreas desmatadas, conforme retrata Amador (1992: 224). Essa destruição da cobertura vegetal fez com que, em médio prazo, a erosão e a lixiviação de nutrientes aumentassem significativamente. A combinação desse fator com o expressivo crescimento populacional do Rio de Janeiro e o sistema ainda rudimentar de distribuição de água potável levou a cidade do Rio de Janeiro a uma crise de abastecimento na segunda metade do século, que foi enfrentada com medidas de proteção ambiental e reflorestamento (Drummond, 1997: 208-211).

Nessa época, os cafezais cariocas entraram em decadência, levando os fazendeiros a procurar um novo ambiente para seu cultivo. De acordo com Dean (2011: 195), era preciso que o solo não fosse encharcado nem seco, de modo que os morros em forma de meia laranja do Vale do Rio Paraíba do Sul foram percebidos como o melhor ambiente. Para Dean:

A planta encontrou na Província do Rio de Janeiro um ambiente adequado, se não [sic] ideal, para o seu cultivo. [...] o café foi a princípio plantado ao longo do litoral, onde pode ter sofrido um pouco com os ventos salinos oceânicos. Logo foi transferido para o planalto um pouco mais fresco, onde se dispõe de uma temperatura ótima de $20^{\circ}$ a $24^{\circ} \mathrm{C}$. A estação seca mais pronunciada do interior também é favorável porque o início das chuvas é o principal indutor da florescência e porque a floração promove o amadurecimento simultâneo dos frutos. A estação seca, de maio até agosto, quando se realiza a colheita, oferece outra vantagem competitiva, porque facilita a secagem dos grãos ao ar livre, um processo que, em outras circunstâncias, teria de ser realizado em fornos a lenha. (Dean, 2011: 195) 
Singer (1977: 208-209) esclarece que, "antes mesmo que ela atingisse o território mineiro, a cafeicultura já proporciona[va] certo mercado aos produtos de criação de Minas, principalmente às bestas utilizadas no transporte de café aos portos de embarque". Quando, em meados do século XIX, o café se espalhou pela Zona da Mata mineira, o projeto cafeeiro prosperou de tal modo que a cultura passou a ser apelidada de "ouro verde". De acordo com Bernardes:

Ao advento da era cafeeira no Brasil Sudeste, deve-se, não há dúvida, a consolidação da posição do Rio de Janeiro como capital e sua grande expansão no século XIX. Em efeito, o Rio de Janeiro, que já era a capital político-administrativa do país, se constituiu em capital econômica de sua mais rica região agrícola à qual também servia de porto. Era o porto através do qual se exportava grande parte da produção cafeeira e se importavam escravos e artigos manufaturados; era, ao mesmo tempo, a corte, onde vinham residir os barões do café, que aqui realizavam seus negócios e organizavam novas empresas, visando a melhoramentos nas velhas estradas e à abertura de modernas vias de circulação, as ferrovias. (Bernardes, 1987: 32)

O espaço dominado pelo café apresentava inúmeras contradições que, em certa medida, foram empecilhos ao desenvolvimento de formas de produção plenamente capitalistas, entre as quais destacamos o regime de sesmarias e o trabalho escravo. Isso indica um traço nítido do desenvolvimento desigual do capitalismo em sociedades periféricas, que é a combinação de práticas capitalistas e não capitalistas de produção. 0 sistema de doação de terras denominadas sesmarias era, além disso, um grande impulso para a devastação da floresta atlântica. Uma vez esgotados os solos, os donos simplesmente as abandonavam e requisitavam uma nova sesmaria ao Governo Imperial. Dean (2011: 195-196) afirma que esse procedimento foi ainda reforçado pela crença de que o café só prosperaria se plantado em solos cobertos por floresta "virgem" e pelo fato de as técnicas de adubação terem sido ignoradas por anos na província fluminense (Dean, 2011: 201):

Em geral, os pés de café assim plantados e cuidados começavam a decair no prazo de vinte anos de maturidade. A senescência marcava o fim da vida produtiva da própria fazenda. Quando um cafezal se tornava tão decadente que não mais valia a pena ser colhido, era eventualmente podado, o que em geral dava apenas magros resultados. Na maioria das vezes, era deixado no lugar, as árvores arrendadas a comerciantes de lenha; o mato então invadia, seguido pelo gado, muitas vezes sob uma nova administração. [...] A floresta não se restabelecia, portanto. (Dean, 2011: 202-203)

Moreira (1990: 31) explica que, ao contrário das outras áreas plantacionistas, os cafezais do Vale do Rio Paraíba do Sul estavam em franca expansão quando começaram, na década de 1850 , as medidas parciais de abolição da escravatura. A proibição do tráfico interatlântico de escravos pela Lei Eusébio de Queirós fez com que os cafeicultores da região tivessem de comprar escravos de outras regiões. Há aqui um exemplo claro do desenvolvimento geograficamente desigual, expresso pela transferência geográfica de capitais, ou melhor, de renda capitalizada, principalmente na forma de escravos: ${ }^{3}$ contraditoriamente, "o mesmo auge cafeeiro que reforça o regime escravista em suas terras o condena nas áreas decadentes como as do espaço canavieiro e pecuário do Nordeste, [...] acelerando nelas a metamorfose da escravidão" (Moreira, 1990: 31):

A desagregação do escravismo conduz à valorização da terra, uma vez que com a crise escravocrata a fonte do poder senhorial desloca-se do controle dos escravos para o controle da terra. Por isso, a classe senhorial, por intermédio do Estado, procura regular juridicamente esta dupla metamorfose em curso: a do mercado do trabalho e a do mercado da terra. Em 1850, o Estado imperial proclama 
juridicamente o estabelecimento de duas das três instituições (a terceira é o mercado do dinheiro) que marcam o nascimento do mercado capitalista: o mercado da força de trabalho, através do decreto da abolição do tráfico de escravos, e o mercado de terras, através da Lei de Terras, que substitui a Lei das Sesmarias. E seu surgimento num mesmo ano não é mera coincidência. Uma lei vem para regular a outra. Num anúncio público do fim do acesso à terra por meio de concessões pelo Estado, a Lei de Terras estabelece o mercado como regra do caminho. Doravante, só se adquire terra mediante compra. Por conseguinte, só a quem pode comprar fica ela assim franqueada, excluindo-se desse acesso quem não tem recursos, o que quer dizer a quase totalidade da população. Dessa forma, embora seja um instrumento de regulação mercantil da circulação da terra, a Lei de Terras se combina com a lei da regulação do mercado de trabalho, uma vez que exclui automaticamente do acesso à terra a quase totalidade da população colonial, à qual só resta oferecer-se em trabalho aos proprietários fundiários. A um só tempo, a Lei de Terras preserva o latifúndio e organiza a nova relação de trabalho. (Moreira, 1990: 36)

Desse modo, avançava-se no Brasil em direção à constituição de um capitalismo mais pleno. Smith (2008: 154) explica que "a equalização das condições de produção [...] resulta da universalização do trabalho abstrato na forma de valor", ${ }_{4}$ o que é incongruente com a existência do trabalho escravo. Sendo assim, o capital submete os demais modos de produção a suas exigências e isto permite o desenvolvimento da divisão do trabalho. Porém, a "universalização da relação salário-trabalho pressagia aos trabalhadores uma liberdade oferecida com uma mão - a liberdade de comprar e vender sua força de trabalho -, mas tomada com a outra"'5 (Smith, 2008: 154). A expressão geográfica disso tudo pode ser encontrada no próprio Marx (1973 apud Smith, 2008: 153), que afirma que, mais que a produção, a "circulação prossegue no espaço e no tempo". ${ }^{6}$

No intuito de expandir a rentabilidade e os próprios cafezais, os agentes privados diretamente interessados e o Estado deram impulso à construção de uma malha rodoferroviária moderna, com uso de tecnologia estrangeira, para garantir o escoamento efetivo da produção de café. Esse sistema de transportes se iniciou com a construção da Estrada União e Indústria, entre Juiz de Fora e Petrópolis, que, em relação à América do Sul, possivelmente foi a maior obra de engenharia à época e seguramente foi a primeira rodovia pavimentada. A expansão das ferrovias também foi importante para o sucesso da cafeicultura. Entre elas, se destacam a Companhia Estrada de Ferro Leopoldina e a Companhia Estrada de Ferro Dom Pedro II, que tornaram ainda mais ágil o transporte do produto. Focaremos nossas atenções, no item a seguir, nas obras da Estrada União e Indústria.

\section{A construção da Estrada União e Indústria, seus trabalhadores e seus condicionantes geomorfológicos}

11 Para o empreendimento da Estrada União e Indústria, entre Juiz de Fora e Petrópolis, o engenheiro e comendador barbacenense Mariano Procópio Ferreira Lage, encarregado da obra, fundou em 1853 a Companhia União e Indústria, em capital aberto, no volumoso valor de 5 mil contos de réis divididos em 10 mil ações. Segundo Vasquez (1998: 23), elas foram "arrematadas em sua maioria pelos ricos plantadores de café, proprietários das fazendas situadas no percurso". O nome União e Indústria fazia referência à união das Províncias de Minas Gerais e do Rio de Janeiro e às indústrias, inclusive a "indústria" do café, que a estrada viesse a estimular. É interessante 
lembrarmos a afirmação de Marx (1967 apud Smith, 2008: 162-163) sobre as empresas de capital aberto: investimentos em infraestrutura imóvel, que em geral requerem um grande volume de capital aplicado, muitas vezes, demandam a reunião de pequenos capitais individuais interessados em realizá-lo; exatamente o que ocorreu com a criação da Companhia União e Indústria.

12 Tendo recebido a autorização imperial em 1852, as obras só foram iniciadas em 1856, após diversas mudanças no projeto original. 0 decreto de D. Pedro II proibia tanto a utilização de mão-de-obra escrava como o tráfego de escravos, o que ocorria em consonância ao projeto abolicionista em curso. Ele previa também a cobrança de pedágio em valor que fosse de acordo com o veículo em tráfego. Para a empreitada, Mariano Procópio contratou o "engenheiro brasileiro Antônio Maria de Oliveira Bulhões, responsável pelo trecho aquém-Paraíba, entre Petrópolis e Três Rios, enquanto o alemão José Keller assumia a responsabilidade do trecho além-Paraíba, de Três Rios a Juiz de Fora" (Vasquez, 1998: 23). Vale lembrar que Três Rios ainda fazia parte do município de Paraíba do Sul (RJ).

Na impossibilidade de contar com o trabalho escravo, Mariano Procópio teve de recorrer aos imigrantes germânicos. Já havia uma colônia de alemães em Petrópolis desde 1845, por ocasião da construção da Estrada Normal da Serra da Estrela; além disso, o governo brasileiro prometia, por lei, terras aos estrangeiros imigrados. Zanei e Lisboa (2011: 9) informam que, com esses incentivos, a Companhia União e Indústria deveria assentar, fora os 150 técnicos, engenheiros e operários iniciais para o trabalho na Estrada, mais três mil colonos - incluídas suas famílias - para a agricultura, a fim de abastecer o mercado interno que entraria em expansão. Para recebê-los, criou-se a Colônia D. Pedro II (Figura 1) em área relativamente afastada do centro de Paraibuna (atual Juiz de Fora). A chegada desses imigrantes deveria ocorrer em pequenas levas, durante diversos meses. Todavia, a casa responsável pela contratação na Alemanha enviou-os atabalhoadamente para reduzir dispêndios, o que fez com que 1.163 pessoas chegassem a curtos intervalos de tempo em meados do ano de 1858. Esse fenômeno elevou repentina e substancialmente a população juiz-forana, que contava com cerca de seis mil habitantes (Vasquez, 1998, p. 84). Tal situação fez com que Mariano Procópio decidisse abandonar a ideia de trazer o restante dos imigrantes. 
Figura 1: Colônia D. Pedro II (Juiz de Fora, MG), em fotografia de Revert-Henry Klumb (ano entre 1863 e 1868)

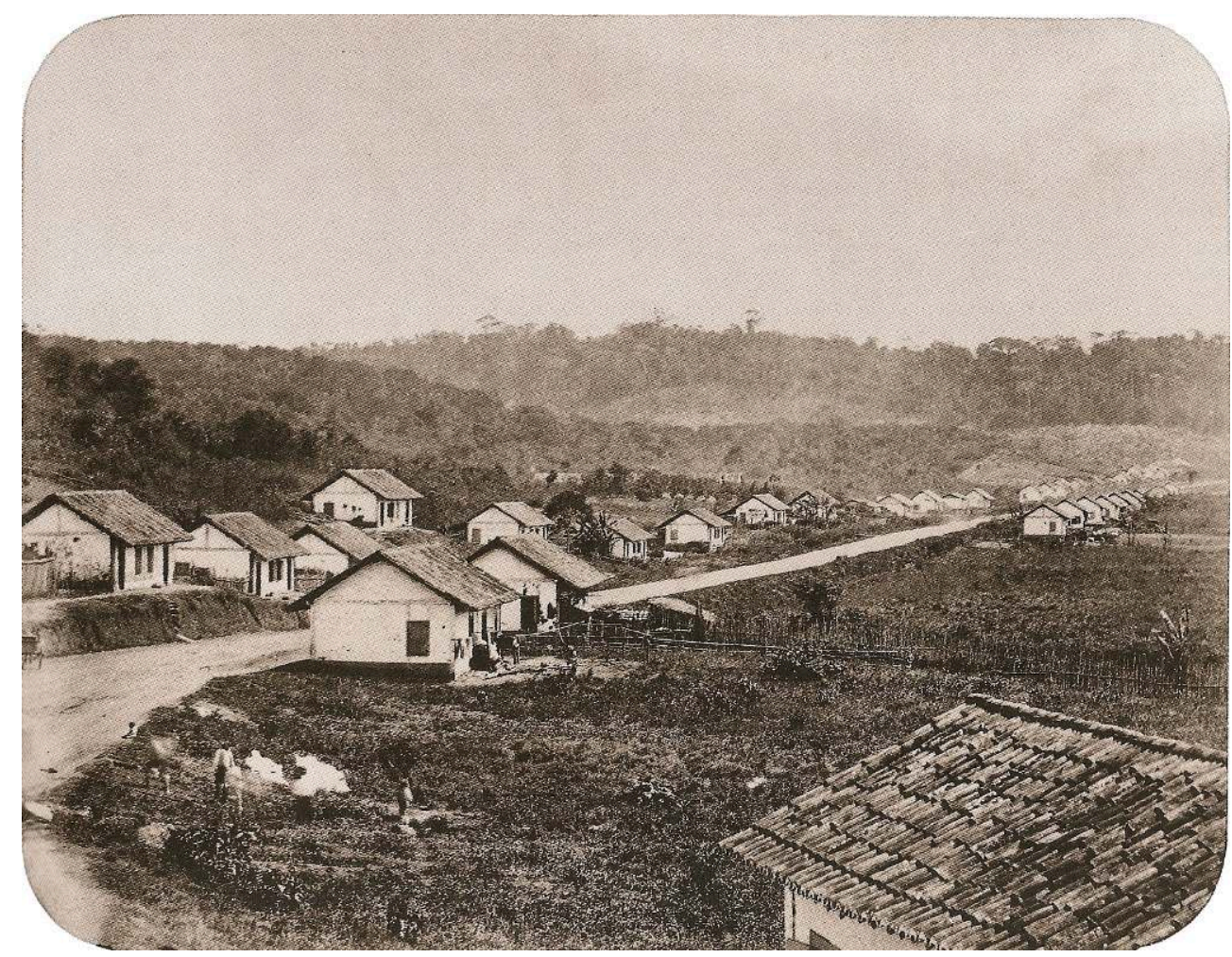

Fonte: Klumb (1872 apud Vasquez, 1998: 85)

Percebem-se, na retaguarda das casas, lotes que possivelmente serviriam para a agricultura. 0 arruamento parece ser aquele que originou a atual Rua Bernardo Mascarenhas, no bairro Fábrica.

De acordo com Dilly (2011: 5), a área foi dividida em duas: a "Colônia de Cima", agrícola, que mais tarde se tornou o atual bairro São Pedro; e a "Colônia de Baixo" ou "Villagen", pretensamente industrial, que deu forma aos atuais bairros Mariano Procópio e Fábrica. Os germânicos, entretanto, se espalharam pela cidade e criaram, inclusive, uma "Colônia do Meio", entre as originais, apelidada de "Sítio do Borboleta" e que hoje consiste no bairro Borboleta. A Colônia contava com uma Escola Agrícola desde 1869, mas devido à baixa demanda foi extinta rapidamente. A Colônia inteira também não se desenvolveu como esperado, principalmente porque o solo era ácido e impróprio para o plantio e porque a maior parte dos colonos não tinha qualquer experiência com agricultura. Sendo eles profissionais das áreas como funilaria, fabricação de carruagens, mecânica, carpintaria, marcenaria e selaria. Mariano Procópio preferiu redirecioná-los para o trabalho nas oficinas e estações da Estrada:

A construção propriamente dita, o corte, a remoção de terras e entulhos, o trabalho braçal, enfim, a abertura da estrada, se deve ao grande contingente de escravos que nela trabalharam. Havia uma proibição contratual que impedia Mariano de utilizar os braços de seus escravos, o que ele resolveu pelo "sistema de arremate", contratos onde proprietários de escravos eram incumbidos de determinados trechos da estrada sob a supervisão da Companhia União e Indústria. (Dilly, 2011: 5)

Aqui vemos um problema eminentemente escalar. Numa escala global, hegemônica, ocorria pressão por parte da grande potência da época, a Inglaterra, pela liberação dos escravos, especialmente através da Bill Aberdeen, lei que autorizava os ingleses a aprisionar qualquer navio negreiro que circulasse no Atlântico. $O$ principal interesse 
subjacente era, obviamente, ampliar o mercado consumidor dos países para o qual a Inglaterra exportava seus produtos manufaturados e industrializados. Na escala nacional, proclamava-se a Lei Eusébio de Queirós, que proibia o tráfico de escravos e dava o primeiro impulso efetivo para o fim da escravidão. Na escala local, referente à construção da Estrada, porém, recorria-se a subterfúgios, como o sistema de arremate mencionado, a fim de escapar às exigências das demais escalas.

Esta questão guarda semelhança com as formulações de Smith (2008) sobre a escalaridade do desenvolvimento geográfico desigual do capital: "Enquanto a escala urbana $^{7}$ é o produto de um processo de diferenciação executado por meio da centralização de capital, ${ }^{8}$ a escala internacional é puramente um produto da tendência para a equalização." (Smith, 2008: 186). Por sua vez, a escala do Estado-nação seria uma espécie de produto da combinação das tendências opostas de diferenciação e igualização do desenvolvimento desigual. ${ }^{10} \mathrm{~A}$ materialização das leis no lugar - e, neste caso, o lugar de que falamos é a ligação entre Juiz de Fora e Petrópolis - não ocorre da maneira como foram concebidas. Proibido contratualmente de usar mão-de-obra escrava, Mariano Procópio lançou mão de outros meios para contornar o decreto imperial e poder usar o trabalho dos negros. A contraditória convivência de formas capitalistas e não capitalistas de produção é um traço muito característico de sociedades de capitalismo ainda não muito desenvolvido, como era o caso do Brasil à época.

17 Curiosamente, a técnica de pavimentação da Estrada União e Indústria também teve de passar por algumas adaptações. Utilizando conhecimentos avançados aprendidos nos Estados Unidos, Mariano Procópio utilizaria o macadame (uma mistura de brita disposta em várias camadas) e alcatrão, mas a impossibilidade de contar com quantidade suficiente desse último material fez o empreendedor optar por um ligante a base de água, como explica Marques (2011: 11). Outra dificuldade enfrentada na construção da Estrada foi na compactação do macadame: primeiramente, porque ela era feita com cilindros de pedra de pelo menos duas toneladas puxados por cavalos, absolutamente difíceis de transportar à época; além disso, a compactação deveria ocorrer num grau específico de umidade, de modo que as obras foram paralisadas diversas vezes em períodos chuvosos e, nos dias mais secos, precisava-se molhar o leito da estrada. Justamente pensando nas frequentes chuvas, Mariano Procópio assegurou que a pavimentação deixasse sempre uma leve inclinação para as bordas a fim de escoar a água (Zanei e Lisboa, 2011: 10).

18 Não obstante essas dificuldades já listadas, nenhuma foi tão grande como a condicionada pelo relevo e pela hidrografia da região. O pouco desenvolvimento da técnica rodoviária, apesar de seu pioneirismo e da utilização das tecnologias mais avançadas, não conseguiu driblar todos os obstáculos. O traçado da estrada, portanto, precisou acompanhar em longos trechos o curso dos rios Piabanha e Paraibuna afluentes do Rio Paraíba do Sul, respectivamente à margem direita e à margem esquerda -, conforme podemos observar na figura 2. Tal traçado apresentava muitas pontes e o leito da estrada foi estabelecido nas planícies desses rios ou, como de costume, à meia vertente. Ambas as localizações do rasgo da rodovia poderiam causar problemas, mas eram as únicas possíveis mediante a técnica disponível. No caso da planície fluvial, as chances de inundação eram muito altas em períodos de cheia, o que interromperia o fluxo por várias horas, mas era também o local de mais fácil construção. Por outro lado, no caso da meia vertente, havia maior possibilidade de o 
corte da encosta feito para a passagem da estrada ampliar a suscetibilidade da área a movimentos de massa, em especial os do tipo slump (ou rotacional), no qual o solapamento da base da encosta a desestabiliza, fazendo-a ceder.

Figura 2: Mapa hipsométrico com a localização aproximada da Estrada União e Indústria, entre Petrópolis (RJ) e Juiz de Fora (MG)

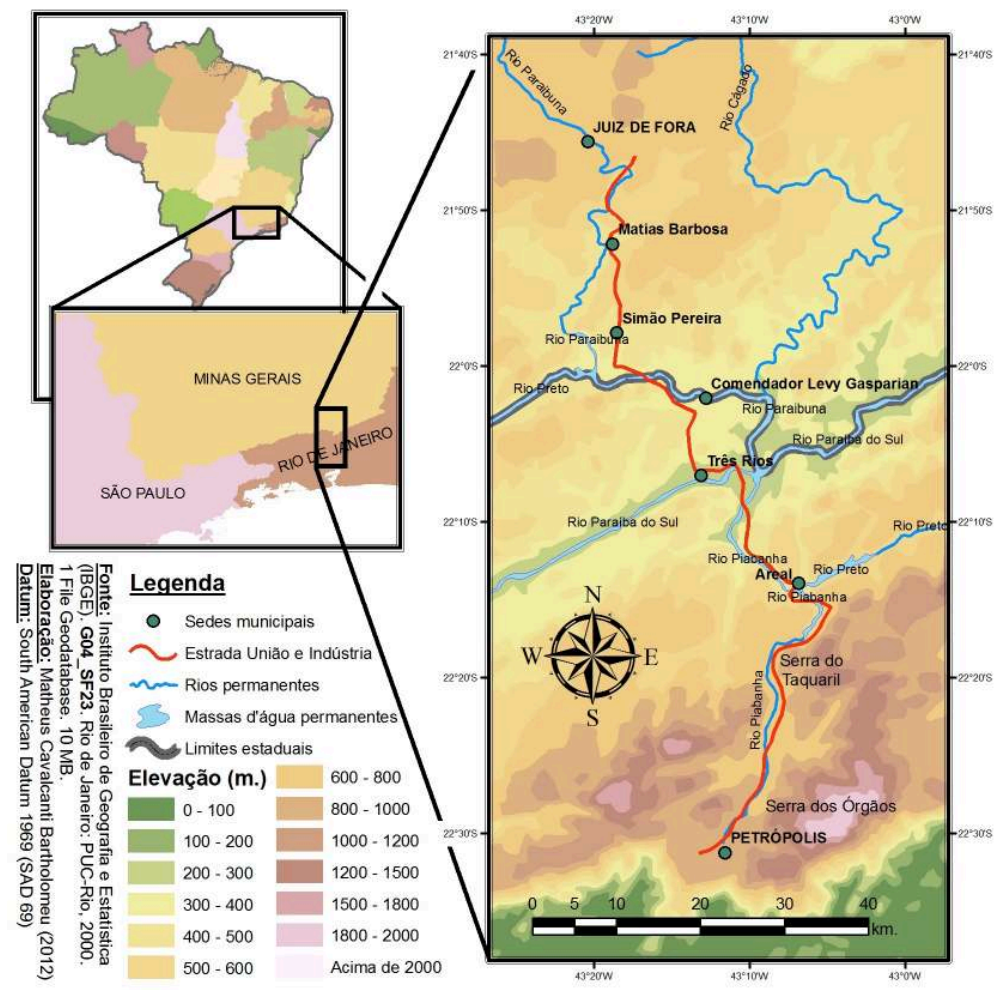

Elaboração: Matheus Cavalcanti Bartholomeu

Os cursos hídricos e as feições geomorfológicas mais notáveis aparecem destacados declive relativamente suave da porção setentrional da encosta, de rede fluvial mais longa, Ruellan (1944: 450) observa que "no reverso do bloco falhado, os rios tributários do Paraíba escavaram vales, geralmente digitados, separados uns dos outros por linhas de grandes picos. Êsses relêvos montanhosos formam serras que separam as bacias fluviais orientadas sul-norte" e propõe que a orientação desses rios teria acompanhado falhas transversais ao curso do Rio Paraíba do Sul. Porém, parece-nos mais razoável a opinião de Lamego de que

a hipótese de falhas não é absolutamente necessária para o seu percurso inteiro. Mas pelo menos uma série de fraturas paralelas deve corresponder à orientação dos rios Ubá, Piabanha, Paquequer Pequeno e Paquequer, em grande extensão dos respectivos cursos, e provàvelmente, na margem esquerda do Paraíba ao trecho final do Paraibuna e ao seu afluente o Rio Cágado. (Lamego, 2007: 37)

Como, de acordo com Lamego (2007: 51), não há evidências de qualquer degrau estrutural na área de confluência tripla dos Rios Piabanha, Paraíba do Sul e Paraibuna, podemos inferir que a própria fratura sobre a qual corre o leito do baixo Piabanha teria mesmo atravessado o Paraíba do Sul a leste da cidade de Três Rios, cortando a Zona da Mata Mineira e determinando o alinhamento N-S dos cursos dos Rios Cágado e baixo Paraibuna. No encontro destes canais, parece também haver outra fratura, esta de 
direção W-E, sobre a qual flui o Rio Preto até seu deságue no Paraibuna, o que determina seu primeiro cotovelo, e que segue delineando o curso do Rio Paraibuna até o Cágado vir a alimentá-lo, à altura de seu segundo cotovelo. Esses cotovelos consecutivos já em 1943 chamavam a atenção de Emmanuel de Martonne (1943: 539). Desse modo, é possível dizer que a Estrada União e Indústria se aproveitou das capturas de drenagem em favor do Rio Paraíba do Sul para penetrar a Serra da Mantiqueira, ainda que esta fosse de transposição mais fácil por causa do relevo já bem mais dissecado e arredondado.

21 Na descida da Estrada União e Indústria podiam-se notar diversas corredeiras e cascatas ao longo do curso do Rio Piabanha. Revert-Henry Klumb, autor do livro "Doze horas em diligencia: guia do viajante de Petropolis a Juiz de Fóra", de 1872, lista e fotografa várias delas, como a Cascatinha (ou Cascata de Bulhões), próxima ao encontro da União e Indústria com a Estrada do Alcobaça, em Petrópolis; e a Cascata dos Correias, no distrito petropolitano homônimo. Sobre o rio, diz ele que "aqui e acolá transforma-se em torrente", possuindo "cachoeiras successivas" (Klumb, 1872: 22). A explicação para a existência dessa marcante geomorfologia fluvial é dada por Ruellan:

Quando os rios se aprofundaram no nível das colinas, nas quais a espessura da camada de decomposição é geralmente grande, encontraram bancos de rochas duras que dificilmente transpuseram e onde persistem rápidos e até mesmo cascatas. Os rios transversais, isto é, orientados sensìvelmente sul-norte, modelaram pois, [sic] uma série de vales largos com fundo chato, inundados por ocasião das cheias anuais, seguidos por gargantas que testemunham uma trabalhosa adaptação apalachiana. (Ruellan, 1944: 452)

Com a evolução da Geomorfologia atual, rapidamente percebemos que Ruellan trata dos sucessivos conjuntos ao longo de um rio formados pela planície de inundação ("vales largos com fundo chato, inundados por ocasião das cheias anuais"), seu estrangulamento por uma rocha mais resistente ("bancos de rochas duras que dificilmente transpuseram") e o knickpoint resultante do vencimento deste nível de base local ("onde persistem rápidos e até mesmo cascatas"). Acerca das inundações, Klumb conta um episódio, que apesar da frase final, da qual havemos de duvidar, é recorrente inclusive atualmente:

\footnotetext{
Alcançamos a ponte do Bom-Sucesso, gracioso trabalho de ferro, systema-vigas direitas e grades.

Esta ponte deve o seu nome ao rio que atravessa e que tem o seu confluente nas águas do Piabanha, por baixo do mesmo arco. Em 1866, na inundação de que ja fallei [ocorrida a 8 de janeiro], as aguas do Piabanha refluírão com uma impetuosidade tal, que a ponte correu graves riscos de destruição ; os pilares ficarão suspensos no vão, sustentando-se só por sua força d'inércia.

Novos trabalhos de consolidação forão feitos depois, e hoje nenhum acidente desta ordem é de temer-se. (Klumb, 1872: 26-28)
}

Com os conhecimentos que temos hoje, não é de se admirar um fato como este de quase 150 anos atrás. Chuvas intensas ocorrem com certa periodicidade na Região Serrana Fluminense, ainda mais no verão. Nestes meses, o fator orográfico da Serra do Mar se combina com a maior umidade das massas de ar oceânicas, o fenômeno da Zona de Convergência do Atlântico Sul e a constituição de grandes nuvens convectivas carregadas. Além disso, mesmo que não chova em toda a extensão dos rios, um acréscimo do volume de água no leito a montante acarreta efeitos multiplicados a jusante em virtude do encontro com demais cursos d'água. Com relação ao Rio 
Piabanha, o caso ainda se agrava, pois suas áreas mais altas se situam justamente na zona mais chuvosa do estado fluminense (IBGE, 1977: 66).

O grande obstáculo na construção da rodovia, porém, foi de fato a Serra do Taquaril (Figura 3). Esta serra é uma porção da Serra do Mar, a norte da Serra dos Órgãos e localizada aproximadamente entre Pedro do Rio e Posse, distritos de Petrópolis. Ela é formada por blocos gigantescos de rocha granítica que, vistos de cima, possuem formato mais ou menos circular. A hipótese mais provável sobre isso é de que essas formas são limitadas por diversas fraturas de orientação N-S e W-E numa espécie de colcha de retalhos, por onde correm os rios que dissecam essas imensas rochas. Além disso, Lamego (2007: 51-52) reconhece que neste setor serrano a fratura do Piabanha sobre a qual falamos parece, na verdade, se configurar como uma falha, o que explicaria a formação dos íngremes paredões. A passagem da Estrada União e Indústria pelo local "exigiu muito de seus construtores: vários altos cortes na rocha (o maior dos quais com $425 \mathrm{~m}$ ), diversos aterros e a construção de muros de arrimo com até $18 \mathrm{~m}$ de altura", como ilustra Vasquez (1998: 42). O texto que Klumb escreve sobre a serra em questão é especialmente poético, mas consegue evidenciar o desafio que a técnica enfrenta com os condicionamentos do relevo:

O valle estreita-se cada vez mais, immensas paredes de granito elevão-se verticalmente de cada lado da estrada, seus flancos quasi perpendiculares conservão nas suas anfractuosidades alguma terra, onde crescem uma multidão de Bromelias. Esta parte da estrada é quasi toda lavrada na rocha, pendora o precipício, no fundo do qual correm roncando as ondas iradas do Piabanha.

Neste lugar do Taquaril selvagem e magestoso existe o único abaixamento desta serra que tínhamos á nossa esquerda desde Petropolis, e portanto o único desfiladeiro possivel para passar do valle superior do Piabanha ao da Posse.

Os trabalhos consideraveis feitos nesta estreita passagem, testemunhão o poder, a vontade e a perseverança humana ; com effeito, representão-se os primeiros mineiros, suspensos a umas cordas sobre paredes verticaes, batendo o duro granito ; por baixo dos pés as detonações das minas repercutidas pelos echos confundião-se com o estrondo das massas de pedras arrancadas pela polvora, e que de queda em queda precipitavão-se no fundo do abysmo. (Klumb, 1872: 34) 
Figura 3: Serra do Taquaril (RJ), em fotografia de Revert-Henry Klumb (ano entre 1863 e 1868).

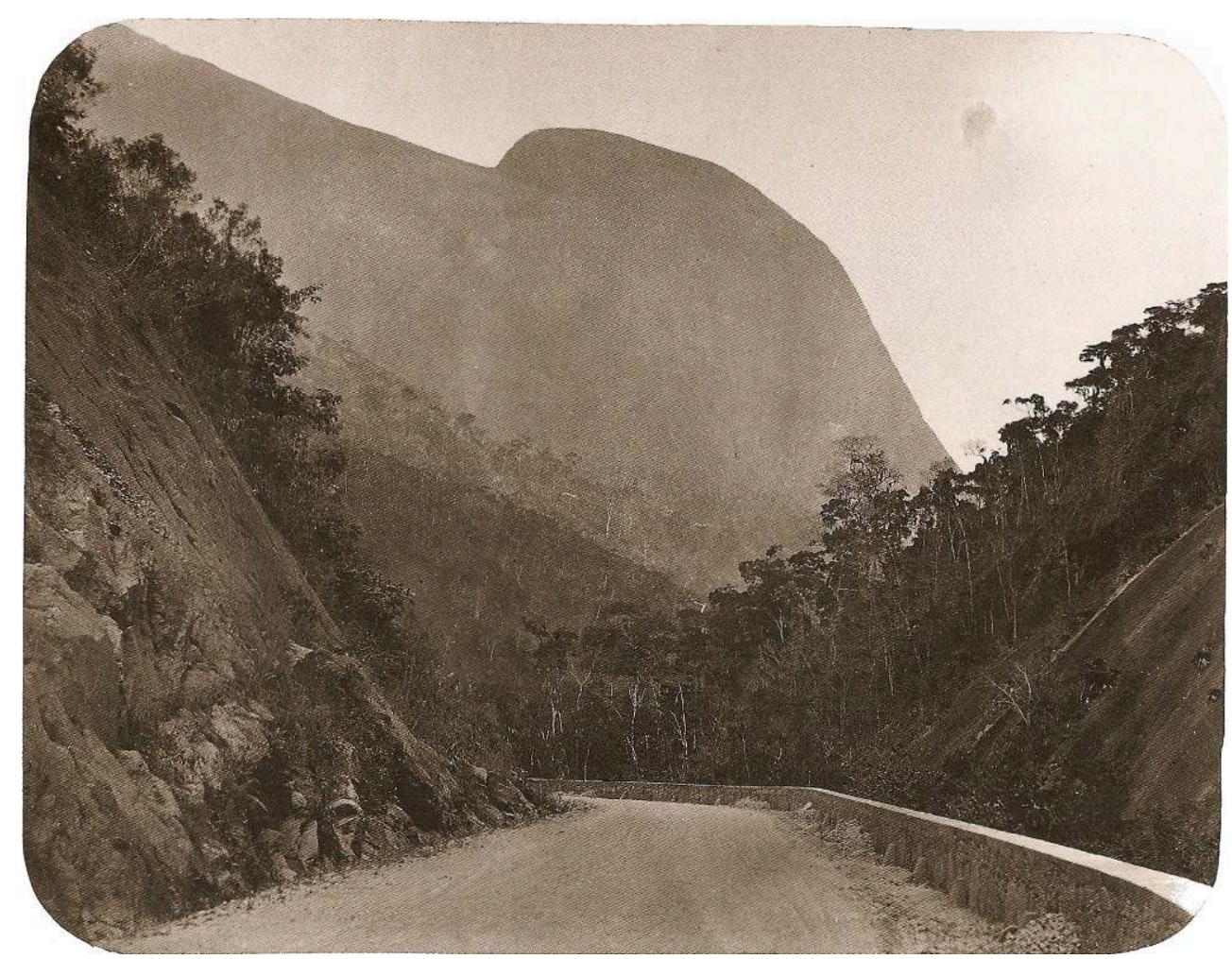

Fonte: Klumb (1872 apud Vasquez, 1998: 42).

Em primeiro plano, a Estrada União e Indústria; ao fundo, um dos paredões rochosos que compõem a serra; à esquerda, percebe-se o corte íngreme da encosta feito pela rodovia.

\section{O papel da Estrada União e Indústria na circulação do café}

No dia 23 de junho de 1861, cinco anos após o início das obras, os $144 \mathrm{~km}$ da Estada União e Indústria foram finalmente inaugurados, em cerimônia na cidade de Juiz de Fora que contou com a presença do Imperador D. Pedro II. As viagens, realizadas em diligências para até 14 passageiros, fora o cocheiro, o condutor e um ajudante, duravam apenas 12 horas e começavam às 6 horas da manhã em Petrópolis ou em Juiz de Fora. Os oito metros de largura média da estrada permitiam que as diligências se cruzassem sem diminuir a velocidade média de $16,3 \mathrm{~km} / \mathrm{h}$, o que tornava bem mais ágil o transporte, principalmente em áreas de tráfego mais difícil, como em aclives ou locais adjacentes a precipícios. Havia 11 estações de muda no percurso, uma distando aproximados $12 \mathrm{~km}$ da seguinte, além das estações final e inicial. Em cada estação, as quatro mulas que puxavam cada diligência eram trocadas por outras descansadas, a fim de prosseguir rapidamente com a viagem.

Além do transporte de passageiros, a Companhia União e Indústria também efetuava o transporte de carga, sendo a principal delas o café, em carroças com capacidade para $3.000 \mathrm{~kg}$ (Marques, 2011: 11). As estrebarias das estações de muda somadas "chegaram a acomodar mil animais em sua fase áurea - 400 mulas reservadas ao serviço das diligências e 600 destinadas às carroças de transporte de mercadorias" (Vasquez, 1998: 62). Em comparação com o modo como o transporte era feito até então, por meio de 
tropas de jumentos cuja carga por cabeça não excedia $60 \mathrm{~kg}$, concordamos integralmente com Giroletti, quando ele destaca que

O sistema de transporte da Companhia União e Indústria (C.U.I.) proporcionou, tanto para fazendeiros quanto para comerciantes, além de maior garantia no escoamento da produção e maior regularidade no abastecimento, uma infraestrutura fundamental que lhes permitiu certas economias de escala, libertando-os dos encargos e do ônus da manutenção de uma tropa particular de muares para garantir o fluxo de mercadorias, e da morosidade e insuficiência dos transportes. É por isto que Mariano Procópio avaliava em 20.000 contos a economia representada pela Companhia União e Indústria ao comércio e à lavoura, nos seis primeiros anos de seu funcionamento. (Giroletti, 1988: 42)

27 No entorno das estações de muda, proliferaram povoados, abrigando inicialmente aqueles que nelas trabalhavam. É o caso, por exemplo, do entorno das Estações de Correias, Pedro do Rio e Posse, que hoje consistem nos distritos homônimos de Petrópolis; da Estação de Julioca, hoje no município de Areal (RJ); da Estação de EntreRios, então no município de Paraíba do Sul, mas hoje na emancipada Três Rios (RJ); e, finalmente, da Estação de Serraria, hoje correspondente ao Centro de Comendador Levy Gasparian (RJ). Outras estações, por sua vez, reforçaram a ocupação já existente desde os tempos do Caminho Novo, como a Estação do Paraibuna, no atual bairro de Monte Serrat, pertencente ao distrito gaspariense de Afonso Arinos; e as Estações de Simão Pereira e Matias Barbosa, nos municípios mineiros homônimos. Esses povoados seriam aquilo que Deffontaines $(1938,144-146)$ chamou de "cidades nas estradas", evoluídas a partir de pousos necessários a longos períodos de tráfego. É interessante notar que algumas destas estações tiveram sucesso apenas efêmero, por conta de a estrada ainda não estar totalmente construída. É elucidativa a análise que Klumb faz sobre a Estação de Pedro do Rio:

Durante os annos de 1858 e 1859, ella recebeu perto de 400,000 saccos de café; em 1867 apenas recebeu 5,187 sacos. É verdade que nos primeiros annos a estrada não ia além, e os lavradores devião, á custa dos maiores sacrifícios, conduzir os seus productos até á estação. Hoje os carros da Companhia recebem os cafés em toda a extensão da estrada e os transportão até o Rio de Janeiro, com uma economia que se póde avaliar em 12,403:000 $\$ 000,{ }^{11} \mathrm{em}$ beneficio da agricultura e do commercio, desde a creação desta magnifica via de communicação. (Klumb, 1872: 32)

A Estação de Pedro do Rio possuía um diferencial até 1959, que era o de ser a mais próxima dos cafezais da Zona da Mata mineira e da porção adjacente do Vale do Rio Paraíba do Sul. Harvey (2006: 97) comenta que as "mercadorias não se levam sozinhas ao mercado: elas são levadas a ele pelos mercadores", ${ }^{12}$ mas também lembra que eles estão sempre em busca de quebrar barreiras espaciais a fim de expandir lucros. Sendo assim, quando a Estrada se aproximou das áreas mais produtivas, o custo do transporte caiu, pois não era mais necessário levar o café até uma estação distante. Isso causou uma diminuição do dinamismo econômico no entorno das estações que foram sendo progressivamente abandonadas como destino de grande parte do produto, ao mesmo tempo em que favoreceu as áreas servidas pela Estrada União e Indústria mais próximas aos cafezais. Essa dinâmica retrata um padrão de desenvolvimento geográfico desigual subjacente ao avanço da estrada em direção a Juiz de Fora. Outro aspecto que podemos perceber é a enorme relevância dos serviços da Companhia União e Indústria para as economias com o transporte. A prova disso é a própria citação a Klumb, pois a Estrada, ainda não concluída, já mobilizava um significativo volume de café de áreas 
relativamente distantes, de modo que aparentemente não havia rotas alternativas que possibilitassem os mesmos rendimentos.

Ainda assim, outras estações, como a da Serraria, mantiveram o recebimento de mercadorias distantes mesmo após a inauguração da Estrada. Sobre esta, Klumb (1872: 54) afirma que "ella tem uma certa importancia para a Companhia, por causa dos productos que aqui chegão do Mar de Espanha [MG, à época situada a $32 \mathrm{~km}$ da estação em questão, segundo o próprio Klumb] e até de Leopoldina [MG, ainda mais longe]". Todavia, dos vários povoamentos ao longo da Estrada União e Indústria, nenhum se beneficiou mais em termos de acumulação de capitais do que Paraibuna, renomeada Juiz de Fora em 1865. Da estrada, partiam ramais para as cidades mineiras de Pomba (atual Rio Pomba), Mar de Espanha, Ubá, Rio Novo e Rio do Peixe (atual Lima Duarte) (Giroletti, 1988: 34), abrangendo boa parte da região cafeeira de Minas Gerais, principalmente a Zona da Mata. Para Giroletti (1988: 40), apesar de parecer, desta maneira, que os capitais gerados pela cafeicultura estariam disseminados pelos municípios onde se produzia café na região, isso não era verdade. Os capitais se concentravam e acumulavam em Juiz de Fora muito mais do que em qualquer outra cidade mineira. As razões para tal

devem ser buscadas na abertura da Rodovia União e Indústria, visto que introduziu uma nova dinâmica no esquema de comercialização da produção local. A abertura da Rodovia União e Indústria vai transformar Juiz de Fora num entreposto comercial. Vai permitir o desenvolvimento do comércio local, tendo como conseqüência maior concentração de capital. Juiz de Fora se transforma, como ponto terminal da mais importante via de comunicação da Província, no local de passagem obrigatória entre Minas e o Rio de Janeiro, no núcleo econômico mais dinâmico da Zona da Mata e polarizador de uma vasta região de Minas e parte de Goiás. (Giroletti, 1988: 41)

Isso que foi explicado agora é exemplo claro de um processo de transferência geográfica de riqueza. Não se trata de transferência geográfica de valor no sentido marxista, porque o trabalho escravo não o pode gerar. Ainda assim, podemos estabelecer uma boa analogia. Para Soja (1983: 66), a transferência geográfica de valor "pode ser definida como o mecanismo ou processo através do qual o valor produzido num local ou numa área é pelo menos parcialmente realizado e, portanto, contribui para a acumulação localizada em outra parte". Ela é, portanto, um produto do desenvolvimento desigual do capitalismo, mas também o direciona, na medida em que contribui para os processos de concentração espacial e centralização do capital. Por conseguinte, conduz também à diferenciação das áreas, uma das tendências do desenvolvimento geográfico desigual. o que vemos no exemplo é, exatamente, a riqueza produzida nos cafezais da Zona da Mata mineira sendo parcialmente transferida para Juiz de Fora, onde se transforma em dinheiro por meio do comércio, mas sem o retorno integral para o produtor.

31 Devido à expressiva economia para os fazendeiros, a Companhia União e Indústria passou a deter o monopólio do transporte na região e, mesmo nos anos em que ainda estava em construção, sequer deixou de transportar mais da metade do café mineiro. "Em alguns anos, sua quase totalidade. Noutros, volume superior àquele exportado pela Província" (Giroletti, 1988: 42), como indica a tabela 1. Isso, entretanto, "não significa que a totalidade do fluxo de mercadorias se originava em Juiz de Fora ou para lá se destinava" (Giroletti, 1988: 43-44) e ainda não permite concluir como verdadeira a afirmação de que a cidade se tornou um entreposto comercial. 
Tabela 1: Comparação entre a massa total de café exportada pela Província de Minas Gerais e massa total de café transportada pela Companhia União e Indústria entre 1858 e 1868

\begin{tabular}{|l|l|l|l|}
\hline Ano & $\begin{array}{l}\text { A - Café exportado por Minas } \\
\text { Gerais (arrobas) }\end{array}$ & $\begin{array}{l}\text { B - Café transportado pela Companhia } \\
\text { União e Indústria (arrobas) }\end{array}$ & $\begin{array}{l}\text { Razão } \\
\text { B/A }\end{array}$ \\
\hline 1858 & 889.766 & 503.418 & $56,6 \%$ \\
\hline 1859 & 688.946 & 1.082 .172 & $157,1 \%$ \\
\hline 1860 & 1.539 .808 & 1.362 .190 & $88,5 \%$ \\
\hline 1861 & 1.092 .616 & 1.576 .826 & $144,3 \%$ \\
\hline 1862 & 647.707 & 771.598 & $119,1 \%$ \\
\hline 1863 & 994.615 & 986.072 & $99,1 \%$ \\
\hline 1864 & 1.476 .017 & 887.200 & $60,1 \%$ \\
\hline 1865 & 1.303 .748 & 1.309 .006 & $100,4 \%$ \\
\hline 1866 & 2.150 .304 & 1.326 .797 & $61,7 \%$ \\
\hline 1867 & 2.130 .992 & 1.982 .259 & $93,0 \%$ \\
\hline 1868 & 2.793 .555 & 1.673 .622 & $59,9 \%$ \\
\hline
\end{tabular}

Fonte: Giroletti (1988: 42), modificado.

Façamos uma breve digressão para falar da importância da União e Indústria para Petrópolis. Uma coisa já havíamos dito sobre o café nos altos serranos: ele não vingava e, ainda que vingasse em um ou outro lugar, certamente sua produtividade seria bem menor que nas áreas mais baixas do Vale do Rio Paraíba do Sul e da Zona da Mata mineira. As próprias fotografias de Klumb (1872) atestam isso, posto que não mostram qualquer vestígio de cafezais nas localidades próximas à cidade de Petrópolis. Essas evidências aparecem à medida que o trajeto descia a bacia do Rio Piabanha, aproximando-se do Paraíba do Sul. Sendo assim, Petrópolis não beneficiou seus cafeicultores com a Estrada, até porque praticamente não existiam. O que trouxe vantagens para a cidade foi o fato de abrigar a estação terminal da rodovia. Todo o café destinado ao Rio de Janeiro convergia para essa estação, de onde iniciava a descida da Serra do Mar, geralmente pela Estrada Normal da Serra da Estrela. Chegando no sopé da serra, as cargas de café alimentariam, então, os serviços náutico-ferroviários do Barão de Mauá. Desse modo, Petrópolis começou a prosperar como uma cidade crucial para o transporte do produto, o que se soma a sua característica de cidade de vilegiatura da Corte Imperial, como mostra Ambrozio (2008: 247). Sobre Petrópolis, Lisboa comenta, atestando a transferência de capitais entre setores da economia:

Com o crescimento da cidade e a presença constante da nobreza, alguns dos colonos começaram a trocar a produção agrícola por outros negócios mais lucrativos. Assim, lojas de chá e pâtisserie, chapelarias, luvarias, sapatarias, entre outros, ofereciam refinados produtos voltados para este público tão exigente. (Lisboa, 2011: 8)

Retornemos de nossa digressão, tornando a falar de Juiz de Fora. Para compreendermos sua condição comercial havemos de considerar a expansão e consolidação da ferrovia como um meio de transporte crucial para a economia cafeeira. Em 1867, a Linha do Centro da Estrada de Ferro Dom Pedro II chegou a Entre-Rios, que, já contando com a 
estação de muda da Estrada União e Indústria, ganhou uma segunda estação, esta ferroviária (Lamego, 2007: 134). Em longa citação, cuja completa reprodução se faz necessária neste texto, Giroletti explica as repercussões da chegada dos trilhos a EntreRios para a Companhia União e Indústria e, finalmente, prova a justeza de caracterizar a Juiz de Fora da época como um entreposto comercial:

À medida que novos trechos da Ferrovia D. Pedro II eram franqueados ao tráfego na região tributária da Rodovia, menor era a capacidade de concorrência da Companhia União e Indústria em termos de volume, rapidez e custos do transporte. Como a concorrência se agravasse e se tornasse nociva tanto para a Rodovia quanto para a Ferrovia, na opinião de Mariano, foi proposto e assinado um acordo pelos diretores das duas companhias, estabelecendo a estação de Entre-Rios como ponto de baldeamento das cargas. Todo o transporte de mercadorias - importação e exportação - de Entre Rios [sic] ao Rio de Janeiro, e vice-versa, era feito pela ferrovia D. Pedro II e das outras estações até Entre-Rios, pela Companhia União e Indústria. O baldeamento de cargas transportadas por esta Empresa em 1869 nos mostra que $40 \%$ do total do volume transportado procediam da estação de Juiz de Fora ou para lá se destinavam. E 55,6\% do total das cargas provinham deste município ou para lá eram enviados [tabela 2].

Se 55\% do volume de cargas se destinavam para o município de Juiz de Fora ou de lá se originavam e se $40 \%$ do fluxo pertenciam ao mesmo núcleo urbano, não restaram dúvidas quanto à existência de um entreposto comercial, nem quanto a seu dinamismo econômico na região, comparado com o fluxo que demandava às demais estações ou que delas provinha. (Giroletti, 1988: 44-45)

Tabela 2: Origem e destino das cargas transportadas pela Companhia União e Indústria e pela Companhia Estrada de Ferro Dom Pedro II em 1869

\begin{tabular}{|l|l|l|}
\hline Estações & Quantidade absoluta (arrobas) & Quantidade relativa (\%) \\
\hline De Entre Rios a Posse & 656.012 & 29,65 \\
\hline De Entre rios a Luiz Gomes & 25.572 & 1,16 \\
\hline De Entre Rios a Serraria & 300.826 & 13,6 \\
\hline Subtotal (Província do Rio de Janeiro) & 982.410 & 44,40 \\
\hline De Entre Rios a Paraibuna & 275.330 & 12,44 \\
\hline De Entre Rios a Matias Barbosa & 68.036 & 3,07 \\
\hline De Entre Rios a Juiz de Fora & 886.778 & 40,08 \\
\hline Subtotal (Município de Juiz de Fora) & 1.230 .144 & 55,6 \\
\hline Total & 2.212 .544 & 100,0 \\
\hline
\end{tabular}

Fonte: Giroletti (1988: 45), modificado.

Pouco adiantou o acordo feito entre as duas companhias, pois em 1875 a Estrada de Ferro Dom Pedro II chegou a Matias Barbosa - onde alterou o local do Centro da cidade para o atual, próximo à estação - e a Juiz de Fora, passando ela a monopolizar todo o fluxo de café e outros produtos da região. A extinção da Companhia União e Indústria foi, então, quase simultânea. É interessante saber, no entanto, que mesmo com quedas significativas em seus negócios, várias manobras políticas e de relações pessoais faziam com que os membros da aristocracia do Império raramente deixassem de sê-los. O caso de Mariano Procópio é exemplar: “D. Pedro II, percebendo o prejuízo que causara ao 
amigo com a expansão da ferrovia, convidou-o, em 1869, para presidir a Estrada de Ferro D. Pedro II [...], posição que Mariano Procópio ocupou até sua morte, ocorrida a 14 de fevereiro de 1872" (Vasquez, 1998: 24). Num acontecimento um tanto quanto simbólico, a estação ferroviária de Juiz de Fora foi construída, em 1877, no exato lugar onde anteriormente era a estação final da Estrada União e Indústria. É notável que, após a chegada da ferrovia, a estação juiz-forana da rodovia passou a se comportar como uma rugosidade no espaço, uma forma resultante de uma técnica que se tornou ultrapassada (Santos, 2006: 25-26). Sua demolição e substituição pela estação de trens simbolicamente sugere a maior expressividade da técnica ferroviária.

A presença da ferrovia em Juiz de Fora não levou à decadência da característica de entreposto comercial da cidade; pelo contrário, reforçou-a, tornando Juiz de Fora um importante centro da rede ferroviária mineira, por onde passaram a circular capitais ainda mais numerosos (Giroletti, 1988: 51). De lá, continuava-se a Linha do Centro da Estrada de Ferro Dom Pedro II, mas na Estação de Benfica (atualmente, um bairro juizforano) partia também o Ramal de Lima Duarte, servindo mais seis estações num trecho de $51 \mathrm{~km}$ (Gerodetti e Cornejo, 2005: 29).

\section{Considerações finais}

Apesar do curto período de operação da Companhia União e Indústria, há de se ressaltar seu pioneirismo e sua importância para a economia cafeeira, servindo, como mostra este estudo, como inegável condição geral de reprodução do capital associado à atividade cafeeira. Uma transformação espacial muito significativa que a Estrada ajudou a engendrar - e que a ferrovia certamente não faria da mesma maneira - foi a consolidação de povoamentos, os quais deram origem a várias cidades da atual ligação Rio de Janeiro - Juiz de Fora. A propósito, à exceção do Rio de Janeiro e, em certa medida, de Duque de Caxias (RJ), todas elas surgiram por meio das estradas e caminhos que conduziam o ouro e o café do interior de Minas Gerais aos portos cariocas.

Singer (1977: 211-212), analisando estatísticas de exportação, conclui que a cafeicultura mineira foi reforçada em decorrência da expansão da rede de transportes. Sendo assim, o setor de mercado externo da província de Minas Gerais, do qual o café se tornou o único representante de peso, foi finalmente reconstituído desde o declínio da atividade mineradora. Embora os avanços nas formas de circulação tenham sido destinados primordialmente para a cafeicultura, eles também serviram ao aumento da produtividade de outros setores agropecuários coexistentes na região:

Data desta época o crescimento de Juiz de Fora, que se torna o grande entreposto cafeeiro da época, em Minas, desempenhando o mesmo papel que São Paulo [SP] terá nas décadas seguintes em relação ao café produzido no interior deste estado e que tem que ser reunido para descer a serra e ser exportado. Só que ao contrário do café paulista, o mineiro tem que vencer duas barreiras montanhosas, a Mantiqueira e a Serra do Mar, o que torna o problema do transporte ainda mais espinhoso. (Singer, 1977: 210)

Apesar da interessante comparação que Singer faz entre Juiz de Fora e São Paulo, ele não se esquece - e nós também não devemos - da importância que um lugar em especial ganhava cada vez mais: a cidade do Rio de Janeiro. "Da mesma forma que a mineração, a cafeicultura fará do porto de embarque, situado fora do território mineiro, o verdadeiro centro econômico da província" (Singer, 1977: 212). A função portuária da capital imperial é, portanto, reforçada significativamente. "Efetivamente é o Rio o destino da 
quase totalidade das exportações mineiras de gado bovino e suíno, dos laticínios e derivados do porco, etc... [sic] E, finalmente, é pelo Rio que são importados os produtos que são consumidos em Minas".

Aqui cabe uma reflexão absolutamente pertinente de Santos (1994: 32), que diz que as infraestruturas que existem em determinado lugar não são exclusivamente decorrentes e dependentes da produção realizada neste lugar. Essas infraestruturas também dependem fundamentalmente do destino da produção, de modo que temos que analisar os processos de circulação: o transporte de pessoas, capitais e mercadorias. No caso da ligação Rio de Janeiro - Juiz de Fora, a expansão da rede viária não dependeu somente dos anseios dos cafeicultores da Zona da Mata ou do Vale do Paraíba. Os interesses dos transportadores e financiadores cariocas é um elemento de outro lugar e de outra escala, já que o Rio de Janeiro é a capital do Império. Fora isso, há a influência que provém do mercado externo, da escala global. 0 autor mencionado ainda analisa a situação recíproca, referente ao consumo local, que muitas vezes depende de uma produção distante no espaço, submetida às suas próprias leis e eventualidades. Comumente, a distribuição dos produtos quanto a seu tipo, quantidade e forma, bem como a disposição das infraestruturas serão autônomas ao lugar do consumo.

Tudo isso nos revela aspectos que têm inegável relação com o desenvolvimento geográfico desigual do capitalismo, os quais podemos citar sucintamente e que já não são novidade. Em primeiro lugar, a transferência geográfica da riqueza produzida nos cafezais da Zona da Mata mineira e adjacências, que se dava fundamentalmente em duas etapas. A primeira, quando essa riqueza era realizada em Juiz de Fora, por meio do comércio, sendo então o café transportado pela Estrada União e Indústria e, posteriormente, pelas ferrovias até o Rio de Janeiro. A segunda e mais significativa etapa, na própria capital do Império, onde era exportado e onde ficava a maior fatia dos lucros com a circulação do produto no Brasil. Em segundo lugar, a desvalorização de áreas que antes eram importantes para o transporte do café, como as organizadas em torno das estações da Estrada União e Indústria, as quais foram sendo gradativamente relegadas com a chegada da ferrovia, um meio de transporte mais rápido e menos custoso.

\section{BIBLIOGRAFIA}

Amador, Elmo da S. (1992). "Baía de Guanabara: um balanço histórico". In: Abreu, Mauricio de A. (Org.). Natureza e sociedade no Rio de Janeiro. Rio de Janeiro (RJ), Secretaria Municipal de Cultura, Turismo e Esportes, Departamento Geral de Documentação e Informação Cultural, pp. 201-258.

Ambrozio, Júlio César G. (2008). o presente e o passado no processo urbano da cidade de Petrópolis: uma história territorial. Tese de Doutorado em Geografia - Departamento de Geografia, Universidade de São Paulo, São Paulo (SP).

Bartholomeu, Matheus C. (2016). Desenvolvimentos geográficos desiguais no eixo de urbanização Rio de Janeiro (RJ) - Juiz de Fora (MG): técnica e transformações espaciais entre 1861 e 1980. Dissertação de 
Mestrado em Geografia - Departamento de Geografia e Meio Ambiente, Pontifícia Universidade Católica do Rio de Janeiro, Rio de Janeiro (RJ).

Bartholomeu, Matheus C. (2017). "Em busca de uma construção conceitual mais ampla de 'eixo': compreendendo sua aplicação usual e suas potencialidades teórico-metodológicas”. In: Simpósio Nacional de Geografia Urbana, 15. Anais... Salvador (BA), UFBA.

Bernardes, Lysia Maria C. (1987). “Importância da posição como fator do desenvolvimento do Rio de Janeiro”. In: Bernardes, Lysia Maria C.; Segadas Soares, Maria Therezinha de (Orgs.). Rio de Janeiro: cidade e região. Rio de Janeiro (RJ), Secretaria Municipal de Cultura, Departamento Geral de Documentação e Informação Cultural, pp. 21-36.

De Martonne, Emmanuel (1943). “Problemas morfológicos do Brasil Tropical Atlântico (primeiro artigo)". Revista Brasileira de Geografia, ano 5, n. 4, pp. 523-550.

Dean, Warren (2011). A ferro e fogo: a história e a devastação da Mata Atlântica brasileira. 8. reimp. São Paulo (SP), Companhia das Letras.

Deffontaines, Pierre (1938). "Como se constituiu no Brasil a Rêde das Cidades: I". Bulletin de la Société de Géographie de Lille, ano 59, t. 82, n. 9, pp. 141-148.

Dilly, Roberto (2011). “Os alemães na construção da União e Indústria”. 150 Anos União e Indústria, n. único, p. 5.

Drummond, José Augusto (1997). Devastação e preservação ambiental: os parques nacionais do estado do Rio de Janeiro. Niterói (RJ), Eduff.

Gerodetti, João Emilio; Cornejo, Carlos (2005). As ferrovias do Brasil nos cartões-postais e álbuns de lembranças. São Paulo (SP), Solaris.

Giroletti, Domingos (1988). Industrialização de Juiz de Fora: 1850/1930. Juiz de Fora (MG): UFJF.

Harvey, David (2006). Spaces of global capitalism: towards a theory of uneven geographical development. Londres (RUN), Verso.

IBGE - Instituto Brasileiro de Geografia e Estatística (1977). “Região Sudeste”. In: IBGE. Geografia do Brasil. v. 3. Rio de Janeiro (RJ), SERGRAF.

Klumb, Revert-Henry (1872). Doze horas em diligencia: guia do viajante de Petropolis a Juiz de Fóra. Rio de Janeiro (RJ), Photographia Klumb.

Lamego, Alberto R. (2007). O homem e a serra. ed. fac-sim. Rio de Janeiro (RJ), IBGE.

Lefebvre, Henri (1978). De lo rural a lo urbano. 4. ed. Barcelona (ESP), Península.

Lefebvre, Henri (2008). A revolução urbana. 3. reimp. Belo Horizonte (MG), UFMG.

Lefebvre, Henri (2011). o direito à cidade. 3. reimp. São Paulo (SP), Centauro.

Lisboa, Isabela (2011). “Bohemia e União e Indústria: histórias que se cruzam”. Petrópolis 26, pp. 8-10.

Marques, Geraldo Lúcio de O. "Macadame hidráulico: uma técnica rodoviária usada há 150 anos". 150 Anos União e Indústria, n. único, p. 11.

Martins, José de S. (2013). o cativeiro da terra. 9. ed., 1. reimp. São Paulo (SP), Contexto.

Moreira, Ruy (1990). Formação do espaço agrário brasileiro. São Paulo (SP), Brasiliense.

Ruellan, Francis (1944). “A evolução geomorfológica da Baía de Guanabara e das regiões vizinhas”. Revista Brasileira de Geografia, ano 6, n. 4, pp. 226-506. 
Santos, Milton (1994). Técnica espaço tempo: globalização e meio técnico-científico informacional. São Paulo (SP), Hucitec.

Santos, Milton (2006). A natureza do espaço: técnica e tempo, razão e emoção. 4. ed., 2. reimp. São Paulo (SP), USP.

Singer, Paul (1977). Desenvolvimento econômico e evolução urbana: análise da evolução econômica de São Paulo, Blumenau, Porto Alegre, Belo Horizonte e Recife. 2. ed. São Paulo (SP), Companhia Editora Nacional.

Smith, Neil (2006). “The geography of uneven development”. In: Dunn, Bill; Radice, Hugo (Eds.). 100 years of permanent revolution: results and prospects. Londres (RUN), Pluto, pp. 180-195.

Smith, Neil (2008). Uneven development: nature, capital, and the production of space. 3. ed. Athens (EUA): The University of Georgia Press.

Soja, Edward (1983). “Uma concepção materialista da espacialidade”. In: Becker, Bertha K.; Costa, Rogério H. da; Silveira, Carmen Beatriz (Orgs.). Abordagens políticas da espacialidade. Rio de Janeiro (RJ), UFRJ, pp. 22-74.

Vasquez, Pedro K. (1998). Álbum da Estrada União e Indústria. 2. ed. Rio de Janeiro (RJ), Quadratim G.

Zanei, Ângela; Lisboa, Isabela (2011). “União e Indústria: 150 anos fazendo parte de nossa história”. 150 Anos União e Indústria, n. único, pp. 8-10.

\section{NOTAS}

1. Este trabalho é uma adaptação de parte da Dissertação de Mestrado do autor (Bartholomeu, 2016). A respeito da discussão sobre o conceito de "eixo", da qual nos abstemos por ora, ver Bartholomeu (2017).

2. Os períodos e seus marcos iniciais ou finais devem ser encarados de forma aproximativa e não como compartimentações cronológicas estanques.

3. Segundo concepção de Martins (2013: 38-50).

4. Tradução nossa.

5. Tradução nossa.

6. Tradução nossa.

7. Podemos, sem prejuízo de sentido aqui, substituir "urbana" por "local".

8. Smith (2008) parece não se preocupar muito em distinguir os termos "concentração de capital" e "centralização de capital", mas a elucidação aqui é oportuna, pois acreditamos que o que Smith chama de centralização neste trecho, na verdade se trata de um processo de concentração de capital. Segundo Aglietta (1979: 193, tradução nossa, grifo do autor), a "concentração é a ampliação da propriedade dentro de um processo de valorização". Ele continua (Aglietta, 1979: 195, tradução nossa, grifos do autor): "Enquanto a concentração simples é, dentro do campo do valor, um fato quantitativo de acumulação desigual que conserva a autonomia dos capitais, a centralização é uma modificação qualitativa que remodela a autonomia dos capitais e cria novas relações de competição."

9. Tradução nossa.

10. A título de esclarecimento acerca da concepção de que o desenvolvimento capitalista possui tendências contraditórias para a diferenciação e a equalização espacial, podemos nos apoiar Smith (2006: 189-190). De acordo com ele e resumidamente, a diferenciação reside no fato de que o capital sempre procura se mover para onde encontre melhores condições para sua reprodução, desenvolvendo determinados lugares em detrimento de outros; por outro lado, a equalização reflete a tendência do capital a nivelar as condições de exploração do trabalho e de extração de 
valor e a "aniquilar o espaço pelo tempo" (equalização). Essa dinâmica "estabelece lugares distintos diferenciados entre si e, ao mesmo tempo, os comprime, através das fronteiras, em um único molde" (Smith, 2006: 190, tradução nossa).

11. Leia-se "doze mil, quatrocentos e três contos de réis".

12. Tradução nossa.

\section{RESUMOS}

Inaugurada em 1861, a Estrada União e Indústria, entre Petrópolis (RJ) e Juiz de Fora (MG), foi um empreendimento pioneiro para garantir a circulação da produção cafeeira da Zona da Mata mineira e do vale do Rio Paraíba do Sul fluminense, entre outras regiões. Sua construção, fortemente condicionada por fatores geomorfológicos, e sua operação engendraram importantes transformações do espaço sob sua influência. Essas transformações se inscreveram, por sua vez, num processo mais amplo de desenvolvimento desigual do capitalismo, no qual a Estrada se constituiu como condição geral de reprodução do capital associado à cafeicultura.

Opened in 1861, the União e Indústria Road, between Petrópolis (RJ, Brazil) and Juiz de Fora (MG, Brazil), was a forerunner enterprise in ensuring the circulation of coffee production in Minas Gerais' Zona da Mata and Rio de Janeiro's Paraíba do Sul River valley, among other regions. Both its construction, heavily conditioned by geomorphological features, and its operation engendered important transformations of the space under its influence. These transformations took place in a wider process of uneven development of capitalism, in which the Road came out as general condition for the reproduction of the capital associated with the coffee cultivation.

Abierta en 1861, la Carretera União e Indústria, entre Petrópolis (RJ, Brasil) y Juiz de Fora (MG, Brasil), fue una iniciativa pionera para garantizar la circulación de la producción cafetera de la Zona da Mata de Minas Gerais y del valle del Río Paraíba do Sul en Rio de Janeiro, entre otras regiones. Su construcción, fuertemente condicionada por factores geomorfológicos, y su operación generaron importantes transformaciones del espacio bajo su influencia. Tales transformaciones se inscribieron en un proceso más amplio de desarrollo desigual del capitalismo, en el que la Carretera surgió como condición general de reproducción del capital asociado a la caficultura.

Inauguré en 1861, la Route União e Indústria entre Petrópolis (RJ, Brésil) et Juiz de Fora (MG, Brésil), fut une entreprise pionnière pour assurer la circulation de la production caféière de Zona da Mata de Minas Gerais et du val du fleuve Paraíba do Sul dans l'état de Rio de Janeiro, parmi d'autres régions. Sa construction, fortement conditionnée par des facteurs géomorphologiques, et son opération ont engendré d'importantes transformations de l'espace sous son influence. Ces transformations ont été inscrites dans un processus plus large d'inégal développement du capitalisme, où la Route est devenue en tant que condition générale de reproduction du capital associé à la caféiculture. 
ÍNDICE

Índice geográfico: Minas Gerais, Juiz de Fora, Rio de Janeiro, Petrópolis

Mots-clés: Route União e Indústria, caféiculture, développement géographique inégal, Juiz de Fora (MG, Brésil), Petrópolis (RJ

Keywords: União e Indústria Road, coffee production, uneven geographical development, Juiz de Fora (MG, Brazil), Petrópolis (RJ

Palavras-chave: Estrada União e Indústria, cafeicultura, desenvolvimento geográfico desigual, Juiz de Fora (MG), Petrópolis (RJ)

Índice cronológico: 1850-1875

Palabras claves: Carretera União e Indústria, caficultura, desarrollo geográfico desigual, Juiz de Fora (MG, Brasil), Petrópolis (RJ

\section{AUTOR}

\section{MATHEUS CAVALCANTI BARTHOLOMEU}

Douto

rando do Programa de Pós-Graduação em Geografia/PUC-Rio

Professor Assistente A do Departamento de Geografia/Instituto de Geociências/UFF Bolsista de Doutorado INCT/CAPES, vinculado ao Observatório das Metrópoles (processo n. 88887.159171/2017-00) 